\title{
Palabras pronunciadas por Tomás Quintana López con motivo de la Lección de despedida, por jubilación, dictada por el profesor Sosa Wagner el 7 de octubre de 2016
}

\author{
(Salón de Grados de la Facultad de Derecho. Universidad de León)
}

\begin{abstract}
Excmo. y Magfco. Sr. Rector, Querido maestro, Queridos compañeros y condiscípulos, Estimados alumnos, Señoras y señores:
\end{abstract}

El trascurso de la vida te va poniendo ante situaciones que raramente, en su totalidad, te producen satisfacción o disgusto; en la mayor parte de las ocasiones -afortunadamente, me atrevo a decir- predominan en nuestra existencia los colores mestizos. Si se piensa, seguramente podamos concluir que esto es lo que nos permite resistir.

Hoy a mí y a otros muchos, quizás a todos los presentes, estar aquí, dispuestos a escuchar la lección de despedida de D. Francisco Sosa Wagner como Catedrático de esta casa, que lo ha sido desde el año 1982, nos alegra como pocas cosas, pues supone asistir a la culminación de una vida profesional dedicada fundamentalmente a la docencia y a la investigación, que constituye, como todo el mundo sabe, la razón de ser de la Universidad, y esto es, sin duda, un motivo de alegría para los que le conocemos, máxime cuando a día de hoy seguimos reconociendo en su pensamiento la brillantez intelectual de siempre y en punto a lozanía yo aprecio casi la misma que cuando le conocí, hace ahora cerca de treinta y cinco años; y este desenlace, desde luego, ninguno de los que aún estamos en activo lo tenemos garantizado.

Pero su despedida también, estoy seguro, a todos nos produce tristeza, pues la Universidad y, en particular, la de León pierde a uno de sus más ilustres miembros y yo qué voy a sentir, si la madurez intelectual que supuestamente he ido alcanzando con el tiempo ha contado desde mis lejanos venticuatro años con la guía segura que me ha proporcionado su criterio, en todo momento generosamente ofrecido y nunca impuesto, algo que siempre he tenido por precioso tesoro, pues para un discípulo poco puede ser más valioso que contar, además de con la ayuda, con el respeto del maestro.

Esta faceta de maestro es la que quiero destacar de la vida universitaria del profesor Sosa Wagner en este momento introductorio, previo a su disertación, pues sin olvidar la docencia impartida durante decenios y su actividad como jurista y escritor, ni tampoco sus años de incursión en la gestión de los asuntos públicos al máximo nivel o en la 
política más recientemente, han sido sus enseñanzas y su ejemplo lo que ha permitido que otros pudiéramos avanzar siguiendo su reconocible estela.

Ya antes de su llegada a Universidad de León, pese a su juventud, dejó bien plantada su semilla en la Universidad de Oviedo -de la que procedía- en la que sus dos primeros discípulos pronto alcanzarían la condición de Catedráticos de Universidad, y estos, en un momento de expansión de la Universidad española, particularmente de los estudios de Derecho, fueron acogiendo a algunos de sus más brillantes alumnos para guiarles por el camino que ellos mismos habían transitado algunos años atrás, ayudándoles a convertirse en profesores universitarios. Todo ello, sin reserva alguna, es tributario de Francisco Sosa.

A su llegada a León, como he dicho, en abril de 1982, Sosa Wagner se encontró con dos incipientes profesores, también recién llegados, adornados entonces con la audacia de la juventud, pero ayunos de experiencia, y con muchas ganas de aprender aunque, bien se sabía, iba a implicar muchas renuncias e importantes sacrificios. Uno de esos dos jóvenes, entonces aprendices de profesores, era yo mismo, que tocado por la Diosa Fortuna pronto trabé una preciosa relación personal con Paco, que es como, desde el primer momento, como muestra de cercanía con su discípulo, así me pidió que le llamara. Después fueron incorporándose a la Cátedra otros jóvenes con los mismos deseos que yo mismo había tenido años antes, y todos fuimos aprendiendo al abrigo de nuestro común maestro, alcanzando tres de nosotros - los de mayor edad- la condición de Catedráticos de Universidad respectivamente en los años 1993, 2002 y 2008, a los que se fueron uniendo otros compañeros que hoy siguen avanzando por el mismo camino que nosotros recorrimos antes.

Hasta tal punto ha sido perceptible la huella dejada por el magisterio del profesor Sosa Wagner en sus discípulos de uno y otro lado de la cordillera que desde hace años a los administrativistas de las Universidades de Oviedo y de León se nos conoce como integrantes de la "Escuela Asturleonesa".

Pues bien, expuesto lo que es la realidad, uno se puede preguntar, cómo ha podido nuestro maestro formar tantos discípulos. Ante cuyo interrogante yo no puedo sino dar mi opinión que, necesariamente, tiene que ser sintética pues aquí hemos venido a escuchar al profesor Sosa en su lección de despedida. Permítanme, no obstante, referirme a sus valores, pues es en ellos es los que encuentro la explicación de su éxito como maestro; y del acervo de los que aprecio en Francisco Sosa, voy destacar dos que sobresalen especialmente: su generosidad y su sencillez.

Porque, en efecto, como muestra de su generosidad y como verdadero maestro ha dado sin esperar recibir nada a cambio $y$, menos aún, sin forzar el pago de los favores realizados en el pasado mediante la presentación al cobro de facturas por supuestas deudas imprescriptibles, por ser continuamente recordadas, pues ello, impropio de un maestro, sería el resultado de un vulgar do ut des. La generosidad de Sosa Wagner también ha sido ajena a los celos por los éxitos, pequeños o grandes, que supuestamente podamos haber cosechado sus discípulos, porque como buen maestro estoy seguro que se enorgullece de ellos y los tiene 
como propios. Todo lo contrario, pues, de lo que sucede con quien solo es un aprendiz de Cronos, devorador de sus propios hijos, que obstaculiza y denigra al discípulo desde el mismo momento en que comienza a despuntar, llevado por el miedo, seguramente infundado, a ser superado; sin recordar que el mito griego nos enseña que Zeus no solo escapó a la muerte, sino que triunfó sobre el filicida.

Pero la grandeza del maestro Sosa Wagner también se sustenta en la sencillez y la humildad, como la de aquel general griego que, según cuenta Plutarco en sus Vidas paralelas, y recrea Rubens en su bello Filopómenes descubierto, tal era su grandeza de espíritu que, vestido de forma impropia para su condición de general victorioso, se hizo pasar por leñador para ayudar a la preparación de los fastos que se organizaban en su honor. Porque la sencillez y humildad son atributos del verdadero maestro, que sin hacer vanidosa ostentación de sus méritos ni perseguir su reconocimiento, aunque aquellos sean muchos y relevantes, como lo son los de Francisco Sosa, recibe los laureles con el sonrojo que produce la íntima convicción de que sus merecimientos no son tales o son fruto del azar. El sentido común nos dicta que los reconocimientos y distinciones no se piden, simplemente se reciben con humildad y se deben agradecer.

La generosidad y sencillez, como compendio de los valores que reconozco en la personalidad $\mathrm{y}$, por ende, en el magisterio del profesor Sosa Wagner, necesariamente han tenido que ser debidamente correspondidas por la gratitud de todos nosotros, sus discípulos, pues mi discurso no sería mínimamente coherente $\mathrm{y}$, menos aún, ecuánime si, como he mantenido, sugiero la exigencia de altas cotas para las virtudes del maestro, sin requerir al menos las mismas dosis de lealtad de los discípulos para con él; porque es un hecho que la iniquidad también puede anidar en sus almas cuando se dejan invadir por una suerte de Complejo de Edipo y se obsesionan por superar contra natura al maestro, utilizando para ello, si fuera preciso, las peores artes.

Nadie -y menos yo-, excepto el profesor Sosa, puede juzgar el comportamiento de sus numerosos discípulos hacia él a lo largo de los años, y para este juicio, si lo llegas a realizar, querido Paco, creo firmemente que tu magnanimidad habrá de contribuir a hacer menos severo el veredicto, pese a que nuestra conducta, como la de todos los humanos, sería de todo punto presuntuoso calificarla de irreprochable.

Lo que yo mismo no me perdonaría es haber caído en la ingratitud, el defecto más grave del hombre, al decir de Ortega en su libro de ensayos Ideas y creencias, pues siempre procuro tener presente como máxima de mi comportamiento a D. Alonso, el de Olmedo, que en su integridad de caballero castellano, con referencia a la ingratitud, sentencia que "no vive en buena sangre, que siempre entre villanos reside. En fin, es la quinta esencia de cuantas acciones viles tiene la bajeza humana pagar mal quien bien recibe". 